\title{
Acute pancreatitis due to an impacted juxtapapillary duodenal diverticulum
}

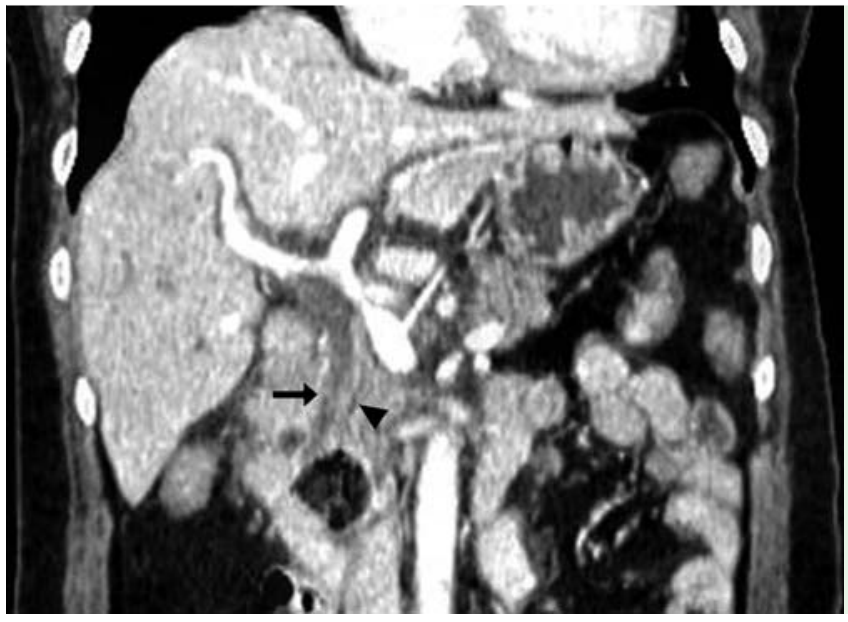

Fig. 1 Abdominal computed tomography (CT) scan showing a round, 2.7-cm, low density lesion with a central area of air density in the second part of the duodenum and swelling of the adjacent pancreas. The common bile duct (arrow) and pancreatic duct (arrowhead) are seen above the lesion.
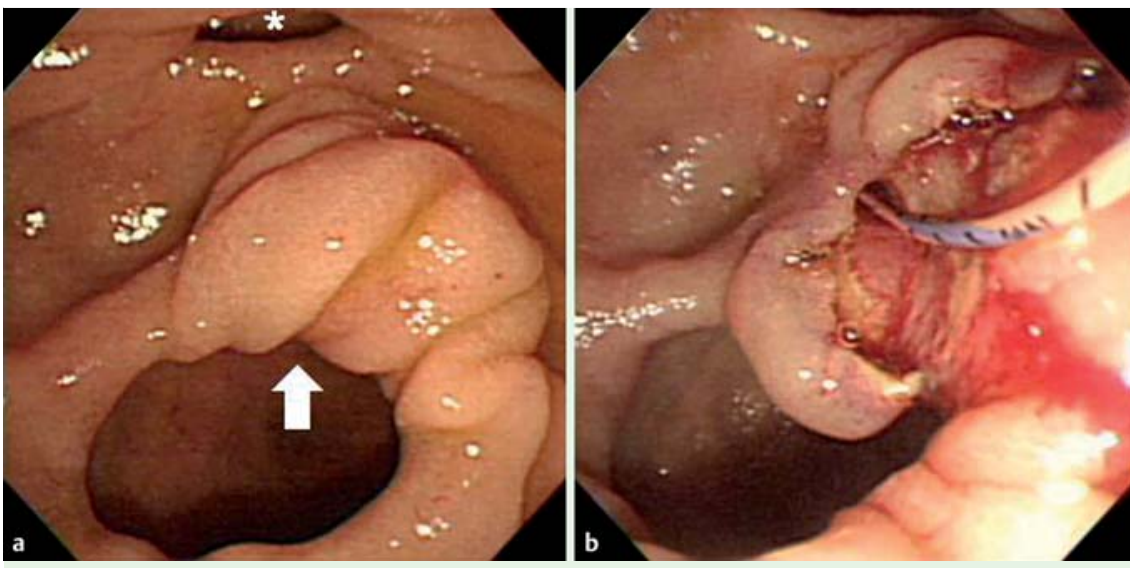

Fig. 3 Views during endoscopic retrograde cholangiopancreatography (ERCP) showing: a a large juxtapapillary duodenal diverticulum (JPDD) located caudally to the papilla and another small diverticulum above (asterisk). The papillary orifice was located deep inside on the ceiling of the diverticulum (arrow) and was not visible without retraction of the mucosa; $\mathbf{b}$ the opening of the papillary orifice exposed outside the diverticulum after an endoscopic sphincterotomy had been performed.

A 58-year-old woman presented with severe abdominal pain. Laboratory findings showed markedly raised amylase and lipase concentrations at $1169 \mathrm{IU} / \mathrm{L}$ and $5040 \mathrm{IU} / \mathrm{L}$ respectively. She denied any alcohol consumption. Triglyceride and calcium levels were within the normal range. An abdominal computed tomography (CT) scan showed a round, 2.7-cm, low density, mass-like lesion with a central area of air density in the second part of the duodenum ( $\bullet$ Fig. 1 ). Esophagogastroduodenoscopy (EGD) revealed a bezoar impacted in a juxtapapillary duodenal diverticulum (JPDD; 0 Fig. 2). The hard phytobezoar was broken up and removed using grasping forceps. After the bezoar had been removed, her pancreatitis improved.

A subsequent endoscopic retrograde cholangiopancreatography (ERCP) showed that the JPDD was located caudally to the papilla with the papillary orifice hardly visible, being located deep inside on the ceiling of the diverticulum. No biliary sludge or stones were noted. A sphincterotomy was performed to prevent recurrence of the pancreatitis ( $\bullet$ Fig.3).

JPDDs are usually located on the cephalic side of the major papilla and may be associated with biliary stasis or relapsing pancreatitis [1-4]. Food or bezoar impaction in a JPDD is known to cause biliary obstruction; however, pancreatitis due to

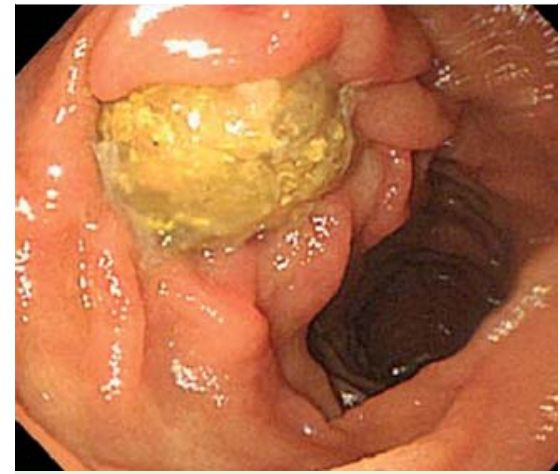

Fig. 2 Esophagogastroduodenoscopy showing a yellowish phytobezoar impacted in a juxtapapillary duodenal diverticulum (JPDD).

bezoar impaction in a JPDD has never been reported, although there are reports of pancreatitis due to impaction of a large bezoar in the duodenal lumen itself [5]. The reason for this seems to be the anatomical proximity of the common type of JPDD to the bile duct rather than the pancreatic duct ( $\bullet$ Fig.4).

In this report, bezoar impaction in a rare caudally located type of JPDD caused acute pancreatitis. This is a rare cause of acute pancreatitis and an unusual clinical manifestation of a JPDD caused by its location.

Endoscopy_UCTN_Code_CCL_1AZ_2AF

Competing interests: None

\section{P. S. Lim, S. H. Kim, I. H. Kim, S. W. Kim, S.-O. Lee}

Division of Gastroenterology, Department of Internal Medicine, Chonbuk National University Medical School and Hospital, Jeonju, Korea

\section{References}

1 Kim MH, Myung SJ, Seo DW et al. Association of periampullary diverticula with primary choledocholithiasis but not with secondary choledocholithiasis. Endoscopy 1988; 30: 601-604

2 Uomo G, Manes G, Ragozzino A et al. Periampullary extraluminal duodenal diverticula and acute pancreatitis: an underestimated etiological association. Am J Gastroenterol 1996; 91: 1186-1188 


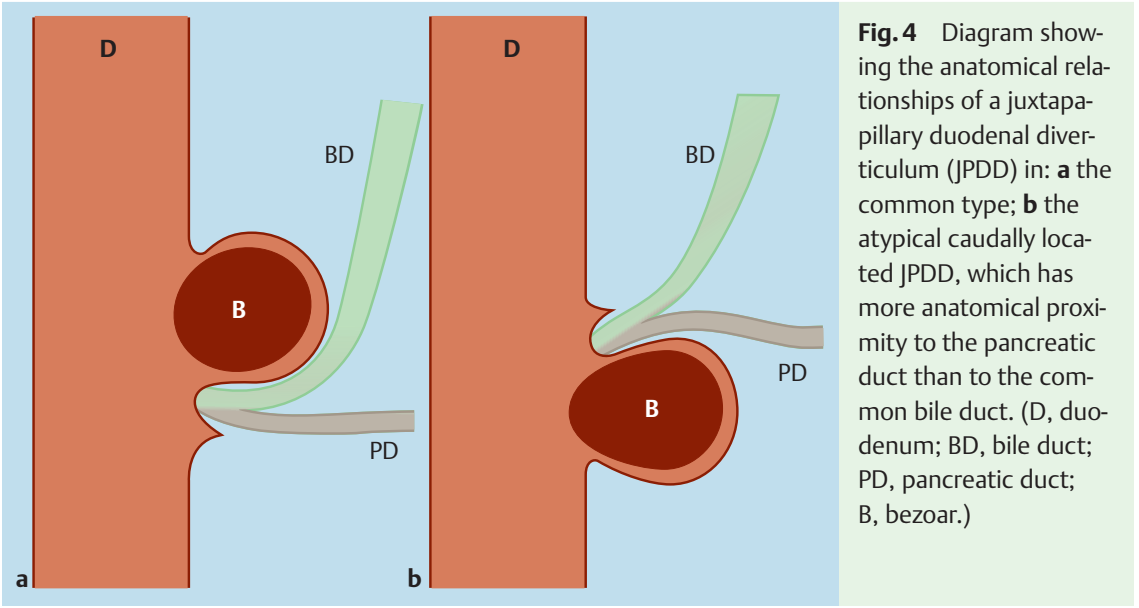

3 Egawa N, Anjiki H, Takuma $\mathrm{K}$ et al. Juxtapapillary duodenal diverticula and pancreatobiliary disease. Dig Surg 2010; 27: $105-$ 109

4 Ichikawa T, Koizumi J, Onoue K et al. CT features of juxtapapillary duodenal diverticula with complications. Tokai J Exp Clin Med 2008; 33: 90-94

5 Katapadi M, Kostandy G, Wang A et al. Can a bezoar cause acute pancreatitis? J Clin Gastroenterol 1997; 24: 120-121

\section{Bibliography}

DOI http://dx.doi.org/

10.1055/s-0031-1291749

Endoscopy 2012; 44: E180-E181

(c) Georg Thieme Verlag KG

Stuttgart · New York

ISSN 0013-726X

\section{Corresponding author}

S.-O. Lee, MD

Division of Gastroenterology and Hepatology

Department of Internal Medicine

Chonbuk National University Medical School and

Hospital

634-18, Geum-am dong

Deokjin-gu, Jeonju

Jeonbuk, $561-712$

South Korea

Fax: +82-63-2541609

solee@chonbuk.ac.kr 